\title{
Multi-dimensional perceived social support as determinant of wellbeing in people with substance use disorder
}

\author{
Salman Shahzad', Nasreen Begum², Sidra Malik³. \\ ${ }^{1}$ Institute of Clinical Psychology, University of Karachi; ${ }^{2}$ Area Study Center for \\ Europe, University of Karachi; ${ }^{3}$ Institute of Clinical Psychology, University of \\ Karachi.
}

Correspondence: email: shahzad_icp@yahoo.com

\begin{abstract}
The objective of this study is to determine the predictive relationship of Multi-dimensional Perceived Social Support (MPSS) with wellbeing in people with Substance Use Disorder (SUD). After detailed review, the following hypotheses were formulated; multi-dimensional social support, i.e., a) Significant others would be a predictor of wellbeing in people with substance use disorder. b) Family would be a predictor of wellbeing in people with substance use disorder. c) Friends would be a predictor of wellbeing in people with substance use disorder. This study comprised 100 treatment seeking patients (people with substance use disorder). The age ranged from 18 to 56 years (mean age $=26.94$ years, $\mathrm{SD}=7.61$ ). The sample was taken from different inpatient treatment and rehabilitation centres for treatment of drug addicts in Karachi and Sindh in Pakistan. A Personal Information Form (PIF) was used to take personal information (age, education, marital status etc.) of the participants. Multi-dimensional Perceived Social Support and Wellbeing Index-WHO were used to measure the MPSS and wellbeing in participants.

In order to interpret the data in statistical terminology, descriptive statistics (mean, standard deviations, variance) was used to get a better statistical view of the summarised data sample characteristics. Simple regression analysis was used to determine the predictive relationship of MPSS with wellbeing in people with SUD. The statistical computation was done through Statistical Package for Social Sciences (SPSS, V-12.0). Results showed that MPSS i.e., significant others $(\mathrm{R} 2=.268, \mathrm{~F}(98)=35.923, \mathrm{p}>.01)$ family $(\mathrm{R} 2=.158, \mathrm{~F}(98)=18.448, \mathrm{p}>.01)$ and friends ( $\mathrm{R} 2=.068, \mathrm{~F}(98)=7.200, \mathrm{p}>.01$ ) are predictors of wellbeing. Overall results indicate social support as a significant predictor of wellbeing in people with SUD. The implications of these results show avenues for future research.
\end{abstract}

Keywords: substance use disorder, multi diamensional perceived social support 


\section{Introduction}

People with SUD have become a problem for health and other social services. They face issues such as medical problems, recurring psychiatric disorders and other social and environmental problems like family dysfunctions, loss of productivity, loss of job, educational problems, accidents and legal issues. All these are very common among people with SUD and are interlinked with each other. Support from other people has a pivotal role in dealing with life challenges. Without this a person's life becomes meaningless in society. Social support serves as a buffer against life's adversities.

Researchers have defined social support in terms of the availability of people whom the individual trusts, and those who can be trusted and who makes a person feel valued and cared for. ${ }^{3}$ According to Weiss perceived social support serves both as instrumental and expressive functions in a person's life, provides social links, nurturance, affiliation and guidance, and also develops self value and intimacy.

The availability of a supportive environment may enhance mental health and as a result the individual is able to overcome obstacles and achieve good mental health. A study conducted by Chou found that a high level of social support from family results in lower levels of depression. Further, research shows that social support from friends results in lower levels of anxiety. Other researchers have also confirmed that social support from family and friends results in lower levels of depression. Similarly, other researchers found that social support and wellbeing have a positive impact on mental health. Research shows the role of social support on an individual's mental health. Studies have been conducted to determine the positive relationship between social support and mental health. Findings from these studies have demonstrated a positive relationship between these variables.

Researchers have studied the potential relationship between drug related coping behaviours and psycho-social distress. These drug related behaviours have been affected mostly by family relations and psychiatric problems. ${ }^{11}$ Wellbeing is a factor that has a direct impact on the individual, family and community. If someone has good mental health then he or she may develop a capacity to contribute to their family friends as well as the community. The absence of good mental health leads to a lack of independence and stress. This can be achieved via internal and external resources. For example, if one has a good support system then he or she may be able to solve problems that affect their mental health. In addition, the person should be resilient enough to fight the adversities of life. ${ }^{12}$

Present research investigates the effects of social support on the wellbeing of people with SUD, residents of drug addiction treatment and rehabilitation centres 
in Karachi, Pakistan. Although much has been said about drug addiction, in terms of psychopathology such as depression, anxiety, etc. little attention has been paid to the protective factors that contribute to the wellbeing of these sufferers. Understanding this association could contribute to the implementation of intervention strategies to help the wellbeing of these people. In light of the review, the following hypotheses were formulated. Multi-dimensional social support, i.e.a) Significant others would be a predictor of wellbeing in people with SUD. b) Family would be a predictor of wellbeing in people with SUD. c) Friends would be a predictor of wellbeing in people with SUD.

\section{Method}

\section{Participants}

The sample for this research comprised 100 poly drug users. The sample was taken from different inpatient drug addiction treatment and rehabilitation centres in different areas of Karachi, Pakistan. The age of the entire sample ranged from 18 to 56 years (mean age $=26.94$ years). The sample consisted of people from a lower socio-economic status. All participants were volunteers and stayed at the treatment for at least 20 days.

\section{Procedure}

This research sample comprised 100 male poly drug users. Before the collection of data, the researchers visited the different inpatient treatment centres to seek permission, and only a few treatment centres gave permission for data collection. The researchers, with the help of staff, identified only those patients who spent at least 20 days in the centres. They were then approached to obtain their consent for participation in this study. The researchers established a rapport with them and they were briefed about the objective of the study, and ethical issues were discussed. The researchers tried their best to maintain ethical standards to safeguard the participants, and confidentiality was assured. Participation in this study was voluntarily.

Researchers interviewed the participants and noted their history of drug use and related problems. After conducting brief interviews, researchers individually administered the MPSS scale and then administered the WHO-Wellbeing Index. The individual administration of all these measures was to maintain the quality of responses provided by each participant and also to monitor the difficulty in understanding each statement in the measures. Out of 300 potential participants only those whose age ranged from 18 to 56 years and whose duration of treatment was at least 20 days were included because they had completed their detoxification during that time period. 


\section{Statistical analysis}

The Statistical Package for Social Science (SSPS, Vol. 12) was used for statistical analysis. Descriptive statistics (mean, SD, and percentages) were used to study the sample characteristics, and simple regression analysis was applied to determine the predictive relationship between variables of the study.

\section{Description of measures}

a) Personal Information Form. A brief semi-structured interview form was developed especially for the current research. The information consisted of items related to the participant's age, gender, residence, education, marital status, duration of drug addiction and duration of stay in the treatment and rehabilitation centres.

b) MPSS scale. ${ }^{1}$ This scale is developed by Zimet et al. and is a 12 item questionnaire to assess perceptions of social support from three specific sources i.e. family, friends and significant others. Each item is rated on a seven-point Likert scale ( 1 = very strongly disagree; 7 = very strongly agree). A total score is calculated by summing up the results for all items. The possible score range is between 12 and 84 and the higher the score the higher the perceived social support. In addition, separate sub-scales can be used by summing up the responses from the items in each of the three dimensions. The possible score range for the sub-scales/dimensions is between 4 and 28.13 The MPSS scale is widely used, and the threefactor model has demonstrated good psychometric properties.

c) Wellbeing Index-WHO (World Health Organization, 1998). ${ }^{2}$ The World Health Organization - Five Wellbeing Index (WHO-5) is a short and quick screening tool for detecting depression levels. It is a self-report measure that consists of five Wellbeing Index items. It is derived from the original version of the Wellbeing Index to measure health-related personal wellbeing, which consisted of 28 items. Researchers reported a good internal and external validity in the second version of the WHO-5 in detecting depression in the elderly. This measure has been used to detect depression in elderly patients diabetic patients and patients in primary care. ${ }^{17}$

\section{Results}

Table I. Descriptive statistics for the age of the sample

\begin{tabular}{llll}
\hline Variables & $\mathbf{N}$ & $\mathbf{M}$ & SD \\
\hline Age & 100 & 26.94 & 7.61 \\
\hline Education & 100 & 5.16 & 4.52 \\
\hline
\end{tabular}


Table 2.Summary of Linear Regression with MPSS as a predictor of the level of wellbeing

\begin{tabular}{lcclll}
\hline Variables & $\mathbf{R}$ & $\mathbf{R 2}$ & $\mathbf{F}$ & Sig & Df \\
\hline Significant others & .518 & .268 & 35.92 & .01 & \\
Friends & .262 & .068 & 7.20 & .01 & \multirow{2}{*}{1.98} \\
Family & .398 & .158 & 18.44 & .01 & \\
MPSS & .470 & .221 & 27.79 & .01 & \\
\hline
\end{tabular}

\section{Discussion}

Table 1 of this study shows the demographic characteristics. Results show the mean age of the entire sample which is 26.96 years $(\mathrm{SD}=7.61)$ and their mean education was $5.16(\mathrm{SD}=4.52)$. Further, the main objective of this study was to examine the predictive relationship of MPSS with the wellbeing of people with SUD. Consistent with the hypotheses formulated in this study, it was found (see Table 2) that MPSS i.e. significant others $(\mathrm{R} 2=.268$, F (98) $=35.923$, $\mathrm{p}>.01$ ) is a significant predictor of the level of wellbeing in people with substance use disorder. Family ( $\mathrm{R} 2=.158, \mathrm{~F}(98)=18.448, \mathrm{p}>.01$ ) and friends $(\mathrm{R} 2$ $=.068, \mathrm{~F}(98)=7.200, \mathrm{p}>.01$ ) is a predictor of the level of wellbeing. The available research suggests the importance of social support. Research shows that the absence of social support can have a negative impact on an individual's health.18,19 The findings of this study are consistent with the previous studies conducted by other researchers. These researchers found a positive relationship between social support and health results in people with HIV.

The results of this research corroborate other studies conducted by researchers, who found that psycho-social support has a significant impact on the health of a person. It could serve as positive catalyst and enhance the psychological immune system of the person. People with SUD in general face numerous issues such as socioeconomic problems, rejection from family, friends and other community members, stigmatisation and discrimination that worsen their problems. Ultimately these could negatively impact on their physical and mental wellbeing. There are a host of social, economic, psychological and cultural concerns about people with SUD in the community. Research shows the significance of support for all categories of people suffering from drug addiction for their wellbeing and also for their positive personality development. The availability of social support from care givers, professional counselors and peers will help them cope better (drug addiction). This may also help them fight the stigmatisation and discrimination that may help in preventing a relapse.

There are limitations in this study that should be considered when interpreting the 
results. The first is that the size is too small to make any generalisation. It is recommended that future research in this area should include a larger sample from more diverse ethnic backgrounds and socio-economic conditions. Provision of a social and emotional wellbeing programme to the patients, families and communities will be effective and helpful to overcome the sufferings of people with drug addiction. This can be done in community settings where awareness programmes can be conducted about risk and protective factors and culturally adapted interventions which should consist of motivational care for social and emotional development.

\section{Acknowledgements}

We are thankful to the Mr. Sohail Younus for facilitating the data collection and all staff of Shaheed Naveed Younus Treatment Center and participants of this study for giving their precious time for providing valuable data.

\section{References}

1. Zimet GD, Dahlem NW, Zimet SG, Farley GK. The Multidimensional Scale of Perceived Social Support. Journal of Personality Assessment 1988;52:30-41.

Doi: http://dx.doi.org/10.1207/s15327752jpa5201_2

2. Wellbeing Index-WHO (World Health Organization). Psychiatric Research Unit, WHO Collaborating Center for Mental Health, Frederiksborg General Hospital, DK-3400 Hillerłd 1998. Retrieved on June, 2012 from http://www.psykiatri- regionh.dk/who5/menu/WHO-5+Questionnaire/

3. McDonald I, Newell C. Measuring health: a guide to rating scales and questionnaires. 2nd ed. Oxford University Press; New York; 1996;523.

4. Weiss RS. The provisions of social relationships. In Doing unto others. Rubin Z. (Ed.) Prentice- Hall, Englewood Cliffs; New Jersey; 1974;180. PMid:4604728

5. Chou KL. Assessing Chinese adolescents' social support: the multidimensional scale of perceived social support, personality and individual differences 2000;28:299-307.

Doi: http://dx.doi.org/10.1016/S0191-8869(99)00098-7

6. Clara I, Cox B, Enns M, Murray L, Torgude C. Confirmation factor analysis of the multidimensional scale of perceived social support in clinically distressed and student samples'. Journal of Personality and Assessment 2003;81:265-70.

Doi: http://dx.doi.org/10.1207/S15327752JPA8103_09

PMid:14638451 
7. Davis MH, Morris MM, Kraus LA. 'Relationship-specific and global perceptions of social support: associations to well-being and attachment'. Journal of Personality and Social Psychology 1998;74(2):468-81.

Doi: http://dx.doi.org/10.1037/0022-3514.74.2.468

PMid:9491588

8. Sowell RL, Seals BF, Moneyham L, Demi A, Cohen L, Brake S. Quality of Life in HV-infected women in the south-eastern United States. AIDS Care 1997;9(5):501-12.

Doi: http://dx.doi.org/10.1080/713613191

PMid:9404393

10. Kahler CW, McCrady BS, Epstein EE. Sources of distress among women in treatment with their alcoholic partners. Journal of Substance Abuse Treatment 2003;24(3):257-65.

Doi: http://dx.doi.org/10.1016/S0740-5472(03)00033-3

11. Lederer, G.S. Alcohol in the family system in F. Brown (ed.) Reviewing The Family Tapesty: A Multigenerational Approach To Families. Family Institute of Westchester, Mount Vernon, WA 1991;219-41.

12. Saskatchewan Health. Healthier Places to Live, Work and Play.A Population Health Promotion Strategy for Saskatchewan. Regina: Saskatchewan Health 2004. 13 Zimet GD, Powell SS, Farley GK, Werkman S, Berkoff KA.Psychometric characteristics of the multidimensional scale of perceived social support. Journal of Personality Assessment 1990;55:610-17.

14. Bonsignore M, Barkow K, Jessen F, Heun R. Validity of the five item WHO Well- Being Index (WHO-5) in an elderly population. European.Arch. Psychiatry Clinical Neuroscience. 2001;251(2):27-31.

15. Awata S, Bech P, Koizumi Y et al. Validity and utility of the Japanese version of the WHO-Five Well-Being Index in the context of detecting suicidal ideation in elderly community residents. International.Psychogeriatry. 2007;19:77-88.

Doi: http://dx.doi.org/10.1017/S1041610206004212

PMid:16970832 
16. Awata S, Bech P, Yoshida S, Hirai M, Suzuki S, Yamashita M et al. Reliability and validity of the Japanese version of the World Health Organization-Five Well-Being Index in the context of detecting depression in diabetic patients. Psychiatry Clinical.Neuroscience. 2007;61:112-19.

17. Henkel V, Mergl R, Kohnon R, Allgaier AK, M ller HJ, Hegerl U. Use of brief depression screening tools in primary care: Consideration of heterogeneity in performance in different patient groups. General.Hospital. Psychiatry 2004;26:190-98.

18. Bastardo YM, Kimberlain CL. Relationship between quality of life, social support and disease-related factors in HIV infected persons in Venezuela. AIDS Care 2000;12(5): 673-84.

Doi: http://dx.doi.org/10.1080/095401200750003842

PMid:11218552

19. Woloshin S, Schwartz LM, Tosteson AN, Chang CH, Wright B, Plohman $J$ et al. Perceived adequacy of tangible social support and health outcomes in patients with coronary artery disease. Journal General Internal Medicines 1997;12(10):613-18.

Doi: http://dx.doi.org/10.1046/j.1525-1497.1997.07121.x

PMCid:PMC1497172

20. Burgoyne, R, Renwick R. Social Support and quality of life over time among adults living with HIV in the HAART era. Social Science Medicines 2004;58(7):1353-66.

Doi:http://dx.doi.org/10.1016/S0277-9536(03)00314-9

21. Stansfeld SA, Bosma H, Hemingway H, Marmot MG. Psychosocial work characteristics and social support as predictors of SF-36 health functioning: the Whitehall Study. Psychosomatic Medicines 1998;60(3):247-55.

PMid:9625210

22. Berkman LF, Syme S. Social networks, host resistance and morality: a nine-year follow up study of Alameda County residents. American Journal of Epidemiology 1979; 109(2):186-204.

PMid:425958 